\title{
Research on marketing strategy: case study of Disneyland
}

\author{
Jia Yao \\ Nanjing University Of Science \&Technology, China \\ *Corresponding author: Jia Yao, Master, 704164535@qq.com
}

\begin{abstract}
:
In April 8, 2011, Shanghai Disneyland starts construction, Shanghai Disneyland will be the second Disneyland in China, at the same time, China will be the only country which has two Disneyland in the world besides the Unite States. This shows the economic strength of China is rapidly growing. Firstly, this article briefly analyzes the marketing environment and market position of Shanghai Disneyland, and then analyzes the global marketing strategy of Disney. Shanghai Disneyland takes these marketing strategies and appropriate innovation marketing according to the national conditions, which can lead to foresee the great success and unlimited development prospects of Shanghai Disneyland.
\end{abstract}

Key words: disneyland; marketing environment; marketing position; marketing strategy

\section{The brief instruction of Disneyland}

Disneyland opened in 1955, since then, the United States and overseas also have opened 5 Disney theme parks, they are located in 4 countries and regions. In September 12, 2005, Hong Kong Disneyland became the first Disney theme park in China, and the Disney Group has ensured the plan that building another theme park in the Chuansha town of Shanghai at that time. By the end of March 2010, there are six places having Disneyland, including the California state, Florida state, Paris, Tokyo, France, Shanghai, and Hong Kong. ${ }^{1}$

Disney Group has been becoming more and more popular nowadays,the number of visitors is becoming larger,which can be shown in the Fig.1.And the Disney Group park's business revenue accounted for much of the total revenue,as the Fig.2 shows below.The success of Disneyland is not only because of the entertainment hardware provided by the high technology, the more important is the quality of service and the management experience, the core part is the Disney business philosophy and management models, including to create a happy atmosphere, to grasp the needs of tourists, to improve the service system and so on. Among them, the Shanghai Disneyland project uses the Japanese Disneyland construction model, implement the 
principles of China holding shares and Staged construction, the theme park project is expected to cost 24.48 billion yuan, the playground part of the area is about 8 square kilometers, surrounded by large supporting area, the first construction area is about 1.5 square kilometers and opened to tourists at the end of 2015. Under the terms of the agreement, Disney will holds $43 \%$ of the shares of Shanghai Disneyland, a joint venture holding company owned by the Shanghai government will holding $57 \%$ of the shares. It is also Asia's second large Disneyland.

Shanghai Disney scenic area has five major characteristics: the most beautiful artificial lake; the world's largest Disney castle; Chinese culture garden; digital park and theme hotel.

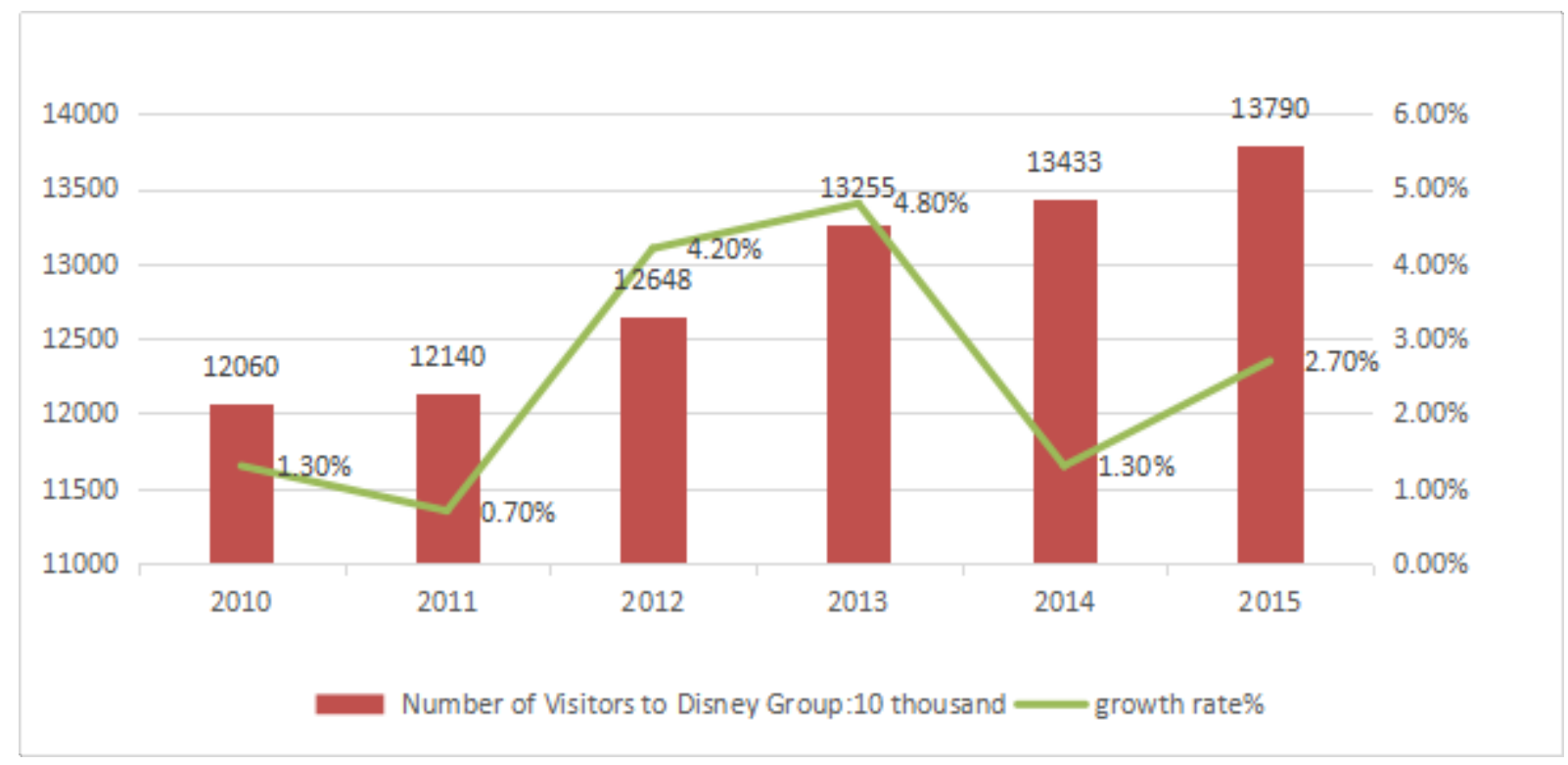

Fig. 1 - The trends chart of visitors to Disney Group from 2010-2015

Data source: The financial statement of Disney. 


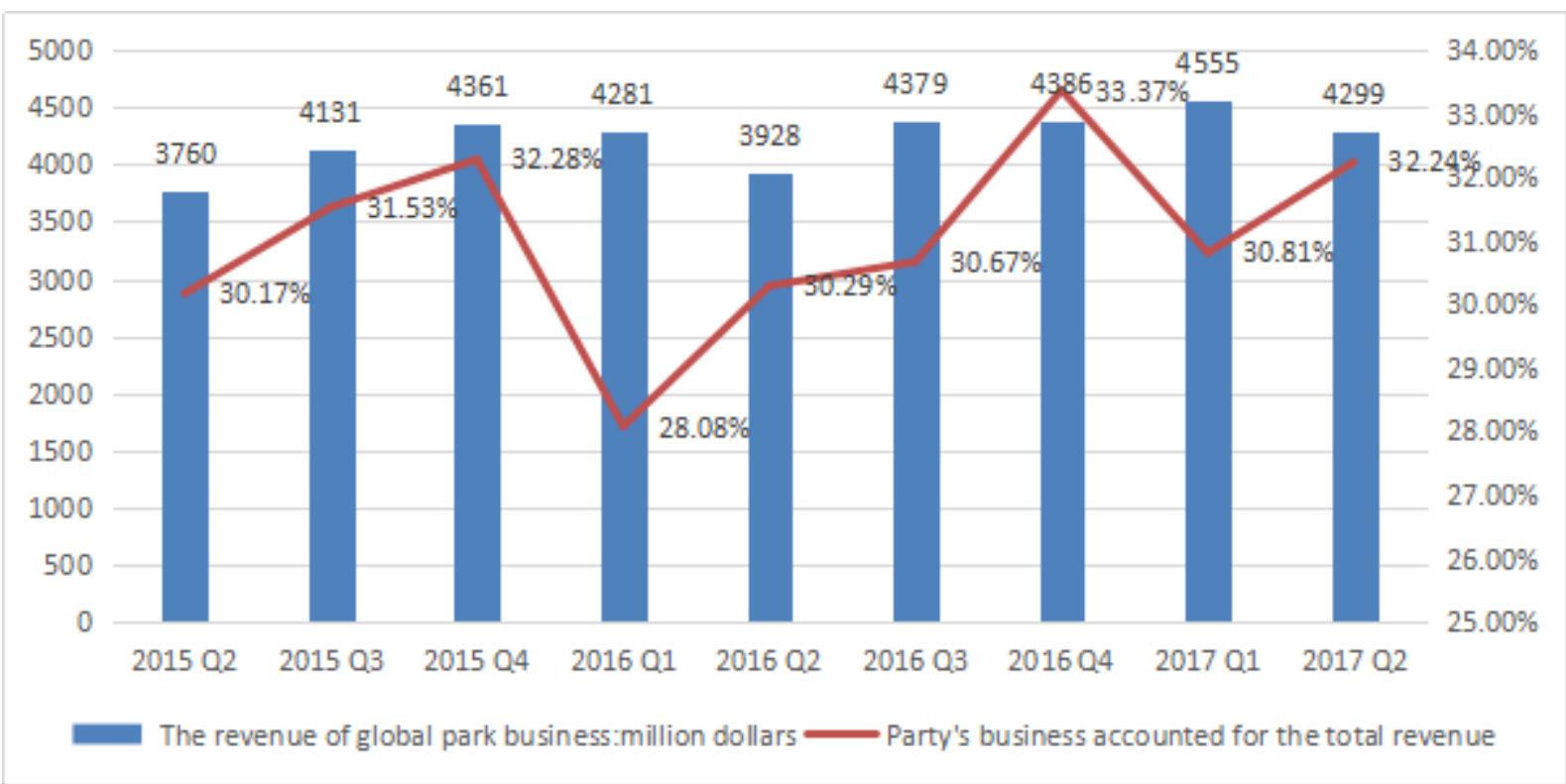

Fig. 2 - Disney Group park accounted for the proportion of total revenue

Data source: The financial statement of Disney.

\section{The development status of Shanghai Disneyland}

From calculation, Shanghai Disneyland average daily reception is 30,000 tourists, it is about 6 times of the Shanghai Happy Valley. According to the official website of Shanghai Happy Valley, totally 15 million people were received in six years from 2009 to 2015, average more than 200 million people per year, average 5479 people per day. Disneyland average number of tourists is about 6 times of the Happy Valley, the popularity is evident.

In the morning of May 10, 2017, Disney released the second quarter of fiscal earnings in 2017. During the three months to April 1st, Disneyland operating income reached 13.34 billion US dollars, higher than 12.97 billion US dollars of the same period last year , an increase of 3\%; quarter net profit was 2.39 billion US dollars, higher than 2.14 Billion of the same period last year, an increase of $11 \%$. Viewed by department, especially spectacular is the Disneyland business, the second quarter of 2017, Disneyland total revenue is \$ 4.299 billion, an increase of 9\%. Disney CFO Kristin McCarthy told the first financial reporter, "theme parks and resorts in the quarter performed strongly, operating income reached $20 \%$ growth, mainly from the business growth of the Shanghai Disneyland resort and the United States theme park and resort.

\section{Marketing environment analysis}

We choose Shanghai Disneyland as the object of analysis , the environmental analysis can be divided into competitor analysis and SWOT analysis. 


\subsection{Competitor analysis}

The "Happy Valley", located in Songjiang District Sheshan National Tourism Resort core area, covers an area of 90 hectares, officially opened in August 16, 2009 , was Shanghai's even the world's largest tourist park, with the most beautiful scenery, the highest content of science and technology . ${ }^{7}$

Jinjiang Paradise is the first large-scale modern amusement park in Shanghai, China, covers an area of 170 acres, a total of 40 amusement projects, suitable for all ages tourists to play, about 1 million tourists per year. In 1998, a total investment of more than 9 million yuan, have built the country's original two projects of "Happy World" and "Canyon rafting"with international level, greatly changing the face of Jinjiang Paradise. ${ }^{7}$

Hong Kong Disneyland is the world's fifth theme park which uses Disneyland model, and the first theme park is California Disneyland (including the sleeping princess castle). Visitors to Hong Kong Disneyland will be temporarily away from the real world, into the colorful fairy tale kingdom, feel the mysterious fantasy future countries and thrilling adventure world. The open of the Disneyland is in 2005, the establishment of Disneyland in Hong Kong greatly promoted the development of Hong Kong's tourism industry. ${ }^{4}$

\subsection{SWOT analysis}

\subsubsection{S: Advantages}

Compared to competing amusement parks, Disneyland has some unique advantages.

(1) High degree of recognition, Disney movies have been deeply rooted in person, Disney becomes synonymous of joy with cartoon image.

(2) Deep brand culture, its service concept is to bring the customers with joy, making the Disney theme park as most people's the first choice for entertainment.

(3) Target group is family, it has clear position and is conducive to maximize the use of their own resources to attract consumer groups.

(4)Focus on innovation and progress, without discarding the core spirit of the premise, adapting to different consumers' demand in the different market, combining the globalization and localization perfectly. With the help of modern technology, entering Disneyland is like entering a fairy tale world.

(5)Quality of Staff service is high, pay attention to experience consumption, in addition to bring consumers a pleasant consumer experience, but also bring them a feeling at home.

6) The design and retail of Disney peripheral product, increasing the income of the park. 
(7) The fully use of the opportunities that China is encouraging the development of tertiary industry ${ }^{2}$

\subsubsection{W: Disadvantages}

(1) Ticket prices are high.

(2) Sometimes the actions of tourists (such as jumping a queue, etc.) will affect the quality of visitors' playing.

\subsubsection{O: Opportunity}

(1)The economy of China's inland has developed rapidly, and the income and consumption level of the residents have improved.

(2) The development of science and technology (high technology and amusement facilities are combined).

(3)The construction of Disneyland increased China's Disney wave, a series of souvenirs have brought a lot of money for the Disney company.

(4) Convenient transportation facilities.

\subsubsection{T: Threats}

(1) Jinjiang Paradise and Happy Valley have resistance on Disney, they have competition with each other.

(2) Japanese and Chinese cartoon become more popular, which has negative impact on Disney's traditional cartoon characters.

\section{Market positioning analysis}

Choose Shanghai Disneyland as an example, Disneyland has a clear market position: the market positioning in all the people who long for happiness or pursuit happiness, is the so-called suitable for both young and old. It has done the professionalization of the market.

Specifically, Disney's market positioning can be divided into brand positioning, business positioning and product positioning. First of all, Disney's brand positioning is to create happy, then sell happy, pay much attention to the experience of consumption, to bring customers unique gaming experience. Make people think of happiness once thinking of Disney. Second, Disney's business position is to expand the company's key strengths - the impact of the film and television business on people; increasing investment in Disneyland and resort business in order to reach the global reach; building Peripheral industry group around the "Disney" brand , to enhance the Disney brand in books, toys and other industries visibility. Finally, Disney's 
product positioning refers to the fact that the product is anything that can be provided to the market that attracts people's attention and meets their needs of happy.

\section{Marketing strategy}

\subsection{Brand strategy}

Brand management refers to the basic trend of the enterprise for the market demand, uses the corporate philosophy as the core, through brand marketing, brand promotion, brand asset management and other business methods to achieve the ultimate goal of maximizing business goals.

Disneyland achieved significant revenue through the implementation of brand management strategies. First of all, the brand management for Disney has won many loyal customers worldwide, forming a differentiated competitive advantage. In the minds of people, Disneyland brand is synonymous of joy, it established a good image of corporate and product, enhance the consumers' recognition of Disneyland, and formed a good reputation among the world, so as to bring it a wide range of source aggregation effect of consumers. Second, the brand management -accelerates the expansion of the Group, promoting the formation of industrial polymerization advantage. Brand management is one of the important and effective means to accelerate the expansion of Disneyland, it can get rid of geographical restrictions, using brand to expand the enterprise's development space and its market size. ${ }^{3}$

Disney brand image can be said to be very successful. Classic Mickey Mouse image can be described as a household name. In addition, there are Donald Duck, three piglets and so many cartoon images having deepened the Disney brand advantages.

In general, the Disney Paradise brand strategy can be divided into three parts: theme park, innovative mode of operation and brand development.

\subsection{1 theme park}

Disney is a dream factory. It moves the plot and story that people can only dream in the dreams to the screen, so that people can see with their eyes and feel it straightly. In the paradise, people will forget many troubles and pressure in their real life, immersed in the fantastic world created by the paradise, so that people really experience all kinds of joy and spiritual enjoyment the Disney brings to them. 


\subsubsection{Innovative operation mode}

In order to maintain Disney's brand advantage, It makes much effort on the innovative mode of operation. In order to highlight the company's brand effect, it often introduces some works with large production, high cost and great scenes. For example, Disney Company invested \$ 125 million in production costs, and invited the famous producer Jerry Brookhimir to produce the work of "Pirates of the Caribbean." The big production can often bring the company high reputation beyond the work itself, and also highlight the company's brand strength. And brand management is precisely one of important and effective ways the Disney Paradise uses to accelerate the expansion. The excellent reputation of the brand with the image of leisure and joy leads Disneyland suitable for different political systems, get rid of geographical restrictions, embarked on the road of rapid expansion.

\subsection{3 brand development}

The brand of disneyland has good image, reputation and visibility in customers, using the Disney brand on theme products, cleverly transfer the consumers' preferences and trust on the disney brand to the new product, rapidly increase the popularity of new products, so that new products can quickly sweep the market. In addition, Disney has also developed a series of products with "Disney" themes, including cartoon characters, themed toys, themed costumes, network products, home appliances, etc., in cooperation with film, television media, network operators, toy manufacturers and clothing dealers.

These expansion and extension for the Disney company has brought huge profits, but also further increased the Disney brand awareness and influence.

\subsection{Experience strategies}

Experience strategies can be broadly divided into sensory experience, emotional experience, thinking experience and action experience. ${ }^{5}$ Disneyland's sensory experience comes mainly from the park layout, such as the park has exciting game projects and three-dimensional films. The so-called emotional experience, refers to the joy of the experience brought to people in the Disneyland, mainly from two aspects: First, from entertainment facilities, the second is derived from the high quality of service. The Thinking experience, that is, for customers to create awareness and problem-solving experience. After entering Disney, visitors can learn various areas of knowledge in the process of playing. For children and adolescents, Disney will design different cultural and educational activities based on different ages and gender characteristics. Finally, through personal interaction to get the action experience, visitors can 
visit the parade together with the actor Mickey Mouse, Donald Duck, Snow White and other fairy tale , besides, they have the opportunity to become superstars and to participate in film shooting in film studios.

\subsection{Product innovation strategy}

"Disney is never built up" is a famous slogan in Disney, over the years, Disney has always insisted on the use of "three-three" system, that is, eliminating one-third of the hardware equipment every year, building one-third of new concept Projects and adding updated entertainment contents and facilities every year that continue to bring freshness to visitors. ${ }^{5}$

The driving force behind Disney's innovative products is "meeting customers' needs." The company will grasp the dynamic needs of tourists based on these analyzes, so as to innovate products, update facilities and equipment. The success of the Disney Paradise's product innovation strategy also illustrates the fact that the theme park can only extend its life cycle as much as possible by constantly innovating products and services based on changes in target market customers.

\subsection{Service strategy}

Disney has a very simple slogan: "We create joy." This also tells the way of Disneyland's services. First of all, Disney has high quality of service standard. For example, in terms of security, Disney uses safety features in world attractions, transport, hotels and restaurants that are higher than local regulations. In terms of courtesy, Disney requires staff to be friendly and make the client happy; in the terms of performance: Disney provides customers with wonderful uninterrupted entertainment services. In terms of efficiency: by analyzing the sales level to provide the right product service portfolio to determine the speed of service and to ensure that customers get the best garden experience. ${ }^{6}$

Secondly, Disney specially pays attention to detail. Take a very classic example, in the Disneyland, the salesman's eyes must be at the same level with the customer's. If the guests are children, the clerk must squat on the ground with a smile, so that eyes and eyes keep the same height and pass products to the children with smile. "The devil exists in the details", the increasingly fierce competition in the market needs more and more attention to service competition.

Thirdly,Disneyland pays more attention to the safety of tourists. In every holiday, due to increased traffic congestion caused by crowded chaos, the staff will take actions such as make 
restrictions on the number of admission, change the ways customers move to protect the safety of tourists.

Finally, recognizing and understanding the guests. There are special "listening posts" at the entrance of the park and the main recreational facilities. It can be used to answer customers' questions and collect information from face-to-face surveys of customers. Throughout the paradise, the opinion card can be seen everywhere. This will help them achieve the goal of quality service and adjust the service strategy timely. ${ }^{6}$

\section{Summary}

In the about sixty years since the opening of the first theme park in California, Disney is not only popular and sought after by tourists in the United States, but also in other countries with other cultural backgrounds, such as Japan, France and China. Proving the globalization, superiority and adaptability of Disneyland marketing strategy. Shanghai Disneyland must also imply such basic marketing strategy, pay attention to China's other theme parks which are lack of unique corporate culture characteristics, create joy, establish brands, improve the construction, management and marketing level and implement the concept "global thinking, local implementation"so that building into a theme park with Chinese characteristics and promoting the healthy development of Chinese theme parks.

\section{References:}

1. Jing Xi. Talk about "Disney" culture [J]. Shopping modernization, 26(2008) 25-26

2. Zhou Li. The analysis of Disney investment in Shanghai [J]. Economic Research Guide, 32(2011) 8-9.

3. Liu Wenjun. Disney brand creation and development [J]. Editor of the Friends, 1(2003) 20-22.

4. Deng Zijing. Disneyland's dream journey [J]. Great trade, 1(2006) 50-55.

5.Zeng Zhuoqi. The development strategy of Disney settled in Shanghai [J]. Contemporary economics, 10(2015)18-19

6.Li Yuan. Discuss about the business model of Shanghai Disneyland [J]. Management Exploration, 3(2017) 17-18

7. Gao Yilian.Comparative Analysis of the Business Model of China's Theme Park [J] .Journal of Finance and Economics, (2015) 21 